\title{
Donorcycles: Motorcycle Helmet Laws and the Supply of Organ Donors
}

\author{
Stacy Dickert-Conlin, Todd Elder and Brian Moore \\ Michigan State University
}

November 18, 2010

\begin{abstract}
Traffic safety mandates are typically designed to reduce the harmful externalities of risky behaviors. We consider whether motorcycle helmet laws also reduce a beneficial externality by decreasing the supply of viable organ donors. Our central estimates show that organ donations resulting from fatal motor vehicle accidents increase by 10 percent when states repeal helmet laws. Two features of this association suggest that it is causal: first, nearly all of it is concentrated among men, who account for over 90 percent of all motorcyclist deaths, and second, helmet mandates are unrelated to the supply of donors who die in circumstances other than motor vehicle accidents. The estimates imply that every death of a helmetless motorcyclist prevents or delays as many as 0.33 deaths among individuals on organ transplant waiting lists.
\end{abstract}

Keywords: Helmet laws, traffic safety, organ donation

JEL Codes: I11, I12, I18, K32 
"Motorcycle fatalities are not only our No. 1 source of organs, they are also the highest-quality source of organs, because donors are usually young, healthy people with no other traumatic injuries to the body, except to the head... [a mandatory motorcycle helmet law] could put us out of business - or at least the business of organ transplants."

- Transplant surgeon quoted in "Brain Dead: Why Are There No Mandatory Helmet Laws?" by Jerry Garrett, New York Times online, July 7, 2008.

http://wheels.blogs.nytimes.com/2008/07/07/brain-dead-why-are-there-no-mandatory-helmetlaws/ (accessed February 3, 2010).

\section{Introduction}

Empirical evidence consistently shows that motorcyclist deaths are disproportionately concentrated among those riding without a helmet. Based in part on this evidence, helmetless motorcyclists are perceived as a major source of transplantable organs, particularly within the medical trauma community. ${ }^{1}$ The perceived link between helmet usage and organ donation even motivated two recently proposed (albeit failed) laws: in 2003, California Assembly Bill 1200 and New Mexico Senate Bill 239 would have made consent for organ donation presumed, rather than based on explicit written authorization, for all helmetless motorcyclists killed in traffic accidents. $^{2}$

Despite the perception that helmet usage reduces organ donation rates, no previous research has investigated whether such a link exists. Estimates of the strength of this relationship are essential to cost-benefit analyses of government regulation of helmet use. Currently, costbenefit arguments are based on weighing personal freedoms against the negative externalities associated with helmetless motorcycling, including costs to public health programs resulting

\footnotetext{
${ }^{1}$ For example, Trauma.org, an organization of professionals in trauma and critical care, published a discussion about helmet laws that included several references to "donorcycles" and claims by physicians such as "[w]asn't there a study a couple of years ago which showed organ donations went down by a third when motorcycle helmet laws were strickly (sic) enforced?" http://www.trauma.org/archive/archives/helmet.html (accessed February 9, 2010).

${ }^{2}$ For the specific language of the California and New Mexico bills, see http://info.sen.ca.gov/pub/0304/bill/asm/ab_1151-1200/ab_1200_cfa_20040109_124839_asm_comm.html and http://www.nmlegis.gov/Sessions/03\%20Regular/bills/senate/SB0239.pdf, respectively (accessed February 10, 2010). Under presumed consent paradigms, motorcyclists can "opt out" of being potential donors only by signing a form explicitly prohibiting their organs for use in transplants. As described by Abadie and Gay (2006), several European nations currently operate under a presumed consent paradigm.
} 
from the relatively high rates of injury and death among those involved in accidents (GAO 1991). This study will quantify an additional, unintended cost of government helmet regulation, as measured by its effect on the supply of organ donors.

Using state- and year-specific data on organ donations and variation across states and time in helmet laws, we present evidence that helmet laws reduce organ donation rates. Statewide helmet mandates are associated with roughly 10 percent reductions in the supply of organ donors who died in motor vehicle accidents (MVAs). In contrast, helmet laws are unrelated to the number of organ donors who died due to circumstances other than MVAs, such as homicide or natural causes. As further support for a causal interpretation of the estimates, helmet laws affect organ donation rates only among men, who account for more than 90 percent of annual motorcyclist fatalities, and are also concentrated among those aged 18 to 34 . Our central results suggest that every death prevented by motorcycle helmet laws decreases the number of organ donors by 0.12 . Based on this estimate, along with published estimates of the number of organs recovered per donor, each death that occurs among helmetless riders saves the lives of 0.33 persons on the vast organ transplant waiting lists.

In the following section, we review the history of helmet laws and describe the mechanisms by which helmet laws could influence the supply of organ donors. Section 3 describes the organ donation data from the Organ Procurement and Transplantation Network and how they relate to publicly available traffic fatality data. Section 4 presents the empirical specifications and results, and Section 5 concludes. 


\section{Institutional Details of Helmet Laws and Their Link to Organ Donation}

Between 1966 and 1995, the federal government twice implemented and retracted acts that set guidelines requiring all motorcycle riders to wear helmets. Although federal legislation has never been a strict mandate to states, it has induced substantial swings in state-level legislation through explicit threats to cut federal highway funding to noncompliant states. ${ }^{3}$ No federal helmet legislation currently exists, but state legislatures continue to debate and modify their own helmet laws. Currently, 20 states have universal coverage laws, 27 states have partial coverage laws that typically mandate helmet usage for all riders under age 18, and 3 states do not require any riders to wear a helmet. ${ }^{4}$ Since the most recent federal guidelines for helmet mandates were removed in 1995, six states (Arkansas, Texas, Kentucky, Louisiana, Florida, and Pennsylvania) repealed universal helmet laws, with Louisiana reinstituting their universal law in 2004. Appendix Table 1 lists the timing of these seven law changes, which play a key role in the analyses below.

The decline in the prevalence of helmet laws since 1995 is perhaps surprising in light of strong evidence that these laws increase helmet use and reduce fatalities. Using data from the 2006 and 2007 National Occupant Protection Use Survey (NOPUS), a field study conducted by the National Highway Traffic Safety Administration to measure the use of motorcycle helmets

\footnotetext{
${ }^{3}$ The 1966 Highway Safety Act authorized the Secretary of Transportation to withhold up to 10 percent of federal highway construction funds from any state that did not adopt universal helmet laws. The Act was amended in 1976, eliminating the helmet law mandate and removing the authority to withhold funds. Under the 1991 Intermodal Surface Transportation Efficiency Act, states that enacted both universal helmet laws and seat belt laws would be eligible to receive federal grant money, while states that did not comply would be subject to a 3 percent reallocation of federal highway funds towards highway safety programs. The threat of reallocation was removed with the passage of the National Highway System Designation Act in 1995 (Houston and Richardson, 1995).

${ }^{4}$ For the purposes of this study, partial coverage laws are considered equivalent to having no helmet law due to enforcement difficulties and the high proportion of the riding population facing no restrictions. Although the most common partial coverage law requires helmets for riders under age 18, some states have restrictions for riders under age 15,19 , or 21 . A handful of states currently require helmets for operators with instructional permits, less than one year of riding experience, or less than $\$ 10,000$ of personal injury insurance. All helmet statutes specify maximum punishments for violation; for example, in Georgia, riding without a helmet is punishable by a fine of up to $\$ 1,000$ and one year in jail, but the typical punishment for a first offense is a fine of $\$ 90$. See http://www.iihs.org/laws/HelmetUseCurrent.aspx for more information on current state helmet laws.
} 
and seat belts, we estimate helmet usage rates in states with a universal law to be 97.8 percent, compared to 54.2 percent in states with partial or no laws. Numerous studies using single-state data also find that helmet usage decreases from nearly 100 percent to roughly 55 percent following universal law repeals (see Berkowitz 1981, Dare et al. 1978, Gilbert et al. 2008, Kraus et al. 1995, Lund et al. 1991, Preusser et al. 2000, Struckman-Johnson 1980, Ulmer and Northrup 2005, and Ulmer and Preusser 2003).

Several additional studies measure the effectiveness of helmets in protecting riders in the event of a crash, with arguably the most convincing approach based on within-vehicle variation in survival and helmet use among operator-passenger pairs. Using this approach, Dee (2009) finds that helmets reduce fatality risk by 34 percent. A related literature considers the effects of helmet laws on state-level fatality rates. Estimates based on within-state variation in helmet laws over time suggest that universal helmet laws reduce per capita fatalities by more than 20 percent relative to partial laws and by 27 to 29 percent compared to having no laws at all (Dee 2009, Houston and Richardson 2008, Sass and Zimmerman 2000). ${ }^{5}$

\section{The Logistics of Organ Donation}

Although brain death is rare, occurring in less than 1 percent of all deaths in the U.S., almost all non-living organ donors are brain dead at the time of organ recovery. The crucial distinction between brain death, which involves the irreversible cessation of all brain function, and the more common classification of death (known as "cardiac death") lies in the fact that the heart continues to beat after brain death occurs. Current medical technology allows for essentially indefinite respiration via a ventilator following brain death, so the internal organs

\footnotetext{
${ }^{5}$ A number of additional studies focus on a single state before and after a helmet law change. For examples, see Auman et al. (2002), Bledsoe et al. (2002), Bledsoe and Li (2005), Eberhardt et al. (2008), Kraus et al. (1994), Mayrose (2008), Mertz and Weiss (2008), and Muller (2004, 2007).
} 
receive oxygenated blood and remain viable for transplantation. In contrast, organs deteriorate rapidly following cardiac deaths and are therefore unsuitable for transplantation except in extraordinary circumstances. ${ }^{6}$ If the brain dead patient is otherwise healthy and provided informed consent for donation, either directly or through family members, surgeons instigate the process of organ recovery. ${ }^{7}$

The perception that helmetless motorcyclists are prime organ donor candidates is based on the notion that they can be killed in low-speed, relatively minor collisions which cause brain death but leave the rest of the body in pristine condition. In contrast, a deceased helmeted cyclist or automobile occupant is likely to have been in a violent collision that caused widespread internal damage and cardiac death, both of which are incompatible with organ donation. Although no previous research has documented the effects of helmet laws on brain deaths in particular, the existing evidence linking helmet use to motorcyclist death rates implies that the incidence of brain death is likely to be lower when helmet laws are in place.

The final link between helmet laws and the supply of organs for transplantation involves the transition from brain death to consenting organ donor. Although federal law has always maintained that health care professionals only need the potential donor's consent to recover organs, a practice known as first-person consent, health care professionals typically also seek permission from the potential donor's next-of-kin. Due primarily to low consent rates, donation rates among all potential donors range from 51 to 60 percent according to Howard et al. (2007). Despite this apparent inefficiency in organ procurement, policies such as helmet laws that affect

\footnotetext{
${ }^{6}$ An example of such a circumstance is the growing but controversial practice of "non-heart beating donation", in which patients with non-survivable brain injuries (who are not brain dead because they retain some minimal brain stem function) become donors. Donation in such cases entails removing the patient from a ventilator, typically in the operating room. Once the patient's heart stops beating, the physician declares the patient dead and organs are removed. See http://www.organtransplants.org/understanding/death/ for more details.

7 "Otherwise healthy" individuals are defined as those younger than 70 and lacking contraindications to organ donation defined by the International Classification of Diseases. Table 2 of Guandagnoli et al. (2003) lists these contraindications, which include cancer, HIV, hepatitis, and a number of other blood-borne infections.
} 
the incidence of brain death will likely affect the supply of organs for transplantation. In the remainder of this paper, we measure the magnitude of this effect.

\section{Data}

The U.S. first established a unified transplantation network, the Organ Procurement Transplantation Network (OPTN), under directive from the 1984 National Organ Transplant Act. This act provided the authority to divide the United States into mutually exclusive donation service areas (DSAs), each of which was assigned to an Organ Procurement Organization (OPO). Each OPO is a local monopoly within its DSA, exclusively responsible for coordinating and facilitating donation services. One of OPTN's key initiatives involves the collection and management of data from every donation and transplant occurring in the United States. ${ }^{8}$

The organ donation data used in this paper are DSA-level counts of deceased donors, available on the OPTN website (http://www.OPTN.org). There are 57 operational DSAs in the U.S. that provide data to the OPTN. In most cases, the aggregation from DSA to the state level is straightforward, but some DSAs cover part or all of multiple states. In these cases, we assign the donation statistics for the entire DSA to the state where its OPO is headquartered. Because our identification strategy is based on state variation in helmet laws, this assignment may present problems if deaths from a county in a given state are designated to another state's donor counts. However, as we describe below, our results are insensitive to restricting our analysis to DSAs that include only one state. Aggregating to the state level results in 38 observations per year

\footnotetext{
${ }^{8}$ The National Organ and Transplant Act also outlawed the purchase and sale of organs and established the OPTN with the responsibilities of creating a system for matching organs to individuals. It also established OPOs as clearinghouses for acquiring useable organs, maintaining organ quality standards and allocating donated organs equitably (see http://optn.transplant.hrsa.gov/SharedContentDocuments/NOTA_as_amended_-_Jan_2008.pdf, accessed 5/19/09).
} 
because 13 states do not contain an OPO headquarters (D.C. contains its own OPO); a complete listing of OPO locations can be found at http://unos.org/members/directory.asp.

The OPTN website provides donor counts starting in 1988, along with data on the demographics, medical history, and certification of consent for each donor. ${ }^{9}$ Beginning April $1^{\text {st }}$, 1994, OPTN also reports the donor's circumstance of death, with separate categories for MVAs, other accidents such as falls, child abuse, suicide, homicide, and, as of 1999, natural causes.

Table 1 presents the number of organ donors per million persons by circumstance of death and gender of donor from 1994 to 2007, with all circumstances other than MVAs aggregated to a single "All Others" category. Because the reporting of circumstance of death began in April of 1994, all donors from the first three months of 1994 are listed in the "All Others" category, making recorded MVA donation rates artificially low in 1994. From 1995 to 2007, donations resulting from circumstances other than MVAs rose steadily for both males and females, increasing by roughly 43 percent from 15.29 to 21.85 per million persons. In contrast, donations due to MVAs were essentially flat from 1995 to 2007, declining from 5.43 to 5.36 per million.

Because the MVA category includes donors killed in all motor vehicle accidents, rather than motorcycle accidents in particular, we also use fatality data from the National Highway Traffic Safety Administration's Fatality Analysis Reporting System (FARS) to refine our analysis. ${ }^{10}$ Table 2 summarizes motor vehicle fatalities by vehicle type and gender from 1994 to 2007. Overall fatality rates declined 13 percent, from 156.3 per million persons in 1994 to 135.3 in 2007 , and declined roughly 20 percent (from 147.4 to 118.3 per million) among those in

\footnotetext{
${ }^{9}$ For a sample Deceased Donor Registration Worksheet, see http://www.unos.org/SharedContentDocuments/Deceased_Donor_Registration.pdf.

${ }^{10}$ The full FARS file contains detailed information on every person involved in an accident on public roads that leads to at least one death within 30 days. Our analysis uses fatalities of vehicle operators and passengers aggregated to the state level.
} 
vehicles other than motorcycles. In contrast, motorcycle fatality rates increased by 90 percent over the same period, from 8.9 to 17.0 per million persons. Taken together, Tables 1 and 2 show that the per capita supply of donors killed in MVAs remained roughly constant between 1994 and 2007 in spite of steady decreases in traffic fatalities. Based solely on the yearly averages, it is unclear whether MVA donation rates were stable because of the dramatic increase in motorcycle fatalities or because of other factors, such as better technological methods of organ recovery or higher rates of consent.

Tables 1 and 2 also show substantial differences across gender in donation and death rates. In every year, men account for roughly 90 percent of all motorcycle fatalities but only two-thirds of deaths in other types of vehicles. Because motorcycle fatalities dramatically increased as a share of all MVA deaths between 1994 and 2007, the share of men in MVA deaths also increased over time. Returning to Table 1, MVA donations among men rose slightly from 1995 to 2007, from 3.55 to 3.74 per million persons, while female MVA donation rates fell from 1.89 to 1.71 . These trends are consistent with increased motorcycle deaths being responsible for holding MVA organ donations roughly constant while non-motorcycle fatalities decreased by 20 percent. Moreover, the dramatic differences across gender contribute to the identification strategy we pursue below.

\section{Do Motorcycle Helmet Laws Reduce Organ Donation Rates?}

We next turn to assessing whether helmet laws affect the supply of organ donors. As described above, 38 states headquarter OPOs that report annual data on deceased organ donors. Our primary empirical strategy involves estimating state- and year-specific organ donation rates 
as a function of whether the state had a universal mandatory helmet law in place in that year. We begin by estimating the following model:

$$
\operatorname{Donors}_{s t}=\alpha_{s}+\delta_{t}+\gamma(\text { law })_{s t}+X_{s t} \beta+\varepsilon_{s t},
$$

where Donors $_{s t}$ is a measure of the number of deceased organ donors, $s$ indexes the state in which the OPO is located, $t$ indexes the year, and $l a w_{s t}$ is an indicator for whether state $s$ had a universal mandatory helmet law for at least six months in year $t$. All specifications include a full set of state and year indicators ( $\alpha_{s}$ and $\delta_{t}$, respectively), and we indicate below when we also control for time-varying state-level variables $X_{s t}$. The vector $X_{s t}$ includes the state's population, its square, and separate measures of the fractions of the population aged 18-34, 35-49, 50-64, and 65 and above; state maximum speed limits; separate indicators for whether the state had primaryenforcement and secondary-enforcement mandatory seat belt laws; climate variables correlated with motorcycle ridership (heating degree days and annual precipitation); and indicators for whether the state had an organ donor registry, whether online registration was available, and whether an OPO in the state enforced a first-person consent paradigm. ${ }^{11}$ We weight each observation by the state's population in that year using U.S. Census Bureau estimates. Estimates of $\gamma$ based on (1) capture the association between within-state variation over time in mandated helmet laws and within-state variation in organ donation rates.

Table 3 presents estimates of $\gamma$ from specification (1) separately for donations due to MVAs and donations due to all other circumstances. The top row presents our central estimates, in which Donors $_{s t}$ includes only MVA donors. In column (1), we measure Donors st $_{\text {as }}$ the

\footnotetext{
${ }^{11}$ Information on helmet and seat belt laws comes from the Insurance Institute for Highway Safety's website: http://www.iihs.org/laws/default.aspx. Primary-enforcement seat belt laws specify that police officers may stop vehicles solely on the suspicion that an occupant is not wearing a seat belt. Under secondary enforcement laws, officers may cite vehicle occupants for not wearing seat belts but cannot stop a vehicle solely for this purpose. Data on first-person consent practices, the existence of state donor registries and the ability to sign up for those registries online came from interviews with OPO employees. The National Oceanic and Atmospheric Administration supplied the climate data.
} 
number of donors per million state residents, so the estimate implies that a universal helmet law decreases the supply of organ donors by 0.491 per million state residents, with a standard error of 0.157 (all standard errors are robust to within-state clustering over time). As shown in column (2), inclusion of the time-varying covariates $X_{s t}$ does not markedly change the point estimate. In both cases, mandatory helmet laws are associated with roughly 10 percent reductions in organ donor rates relative to the sample average of 5.148 per million persons. In order to assess how sensitive these results are to the definition of the dependent variable, in columns (3) and (4) we define Donors $_{s t}$ to be the absolute level of organ donors and its natural logarithm, respectively. These specifications lead to similar inferences as those in columns (1) and (2); specifically, helmet laws are estimated to reduce MVA organ donors by roughly 12.7 percent $(=-7.696$ / $60.595)$ when measured in levels and by roughly 9.7 percent when measured in natural logs. Using donors per capita as the dependent variable, as in columns (1) and (2), allows us to interpret the estimated coefficients as the effect of helmet laws on donors among the population at risk to donate, and provides a straightforward interpretation below when we consider the effect of helmet laws on the excess demand for organs. We therefore focus on specifications using per capita dependent variables from this point forward.

The principal threat to the internal validity of estimates based on specifications such as (1) stems from differential unmeasured time trends across states in organ donation rates that may be correlated with the presence of helmet laws. These time trends could reflect hospitals improving their procedures for organ recovery, education campaigns encouraging informed consent, or endogenous law changes in response to declining donation rates. If differential trends drive the negative point estimates in the top row of the table, they would likely also induce a negative association between helmet laws and the number of donors due to circumstances other 
than MVAs. As shown in the "All Others" row of the table, this is not the case - in all four specifications, the point estimates are both positive and statistically indistinguishable from zero at conventional significance levels. The remaining rows of the table present estimates for the individual circumstances that comprise the aggregate "All Others" category. None of these circumstance-specific organ donation rates is significantly related to helmet laws in any specification.

As Tables 1 and 2 showed above, motorcycle fatalities and MVA donation rates differ substantially across gender, so in Panel A of Table 4 we present gender-specific estimates of the effects of helmet laws. Columns (1), (3), and (5) in the first row show the effect of helmet laws on motorcycle fatalities, given by estimates of $\gamma$ based on a specification similar to that in (1):

$$
\text { Deaths }_{s t}=\alpha_{s}+\delta_{t}+\gamma(\text { law })_{s t}+X_{s t} \beta+\varepsilon_{s t},
$$

where Deaths $s_{s t}$ denotes the number of annual motorcycle fatalities per million state residents. Population-weighted average death rates are shown in brackets. Column (1) shows that universal helmet laws decrease deaths among male motorcyclists by 3.962 per million persons, a 39 percent decline relative to the baseline male death rate of 10.218. Column (3) shows that the absolute effect is much smaller among women, 0.395 per million persons. This reduction is roughly 38 percent of the baseline death rate of 1.039, similar to the relative effect among men. Column (5) presents estimates of $\gamma$ based on pooled-gender death rates. The 39 percent reduction (= 4.369 / 11.258) in fatalities is broadly consistent with the findings of Dee (2009), for example, whose estimates range from 27 to 34 percent in specifications using the logarithm of fatalities as a dependent variable. In sum, helmet laws decrease motorcyclist deaths among both genders, but 
the absolute decrease is much larger among men because men account for over 90 percent of all motorcyclist deaths. $^{12}$

The gender-specific fatality estimates in Table 4 suggest an intuitive test for whether the association between helmet laws and organ donors is causal - because helmet laws can influence organ donations only through their effect on motorcycle fatalities, the absolute effects of helmet laws on donation rates should be substantially larger among men than among women. We therefore present gender-specific estimates of the effect of helmet laws on MVA donation rates in the even-numbered columns of Table 4. The results are striking. Helmet laws have large, statistically significant effects on the number of male MVA donors, with the estimate of -0.558 (0.109) being over 16 percent of the baseline male MVA donor rate. In contrast, the estimated effect among women is positive, although the point estimate of $0.015(0.061)$ is both practically and statistically insignificant. Although helmet laws reduce motorcycle fatalities among women, the reduction is sufficiently small relative to the number of female MVA deaths that it does not produce a measurable effect on the supply of female organ donors; as Table 2 showed, only 4 percent of all female MVA fatalities in 2007 involved motorcycles, compared to 16 percent among men. We view this pattern as compelling evidence of a causal effect of helmet laws on organ donations, because the most likely sources of unmeasured confounding trends would affect organ donation rates among both men and women.

\footnotetext{
${ }^{12}$ The similarity across gender in relative effect sizes may result from a similarity across gender in the effects of helmet laws on helmet usage. Mayrose (2008) finds that in a sample of fatally injured motorcycle riders and passengers, the effects of statewide helmet mandates on helmet use are roughly constant across gender, with 83.8 percent of males and 85.8 percent of females wearing a helmet in states with a universal helmet law, compared to only 36.4 percent and 34.9 percent in states with a partial law. NOPUS observational data, which are not limited to those who were involved in a fatal accident, do not differentiate by gender, but these data do allow for estimates of helmet usage separately for drivers and passengers. In our analyses of these data, available upon request, the relationship between helmet laws and helmet usage does not significantly differ between drivers and passengers, suggesting that it also does not differ across gender.
} 
As another check on the plausibility of the results shown above, the remaining rows in Panel A present estimates of equations (1) and (2) separately by the age categories included in the OPTN data. ${ }^{13}$ We again expect the absolute effects of helmet laws on donation rates to be largest among the groups most likely to be involved in motorcycle fatalities, and the results strongly confirm this expectation. Roughly 47 percent $(=4.759$ / 10.218) of motorcycle fatalities among men occur in the 18 to 34 age range, and helmet laws reduce fatalities in this age group by 2.018 , or 44 percent of the baseline rate. Men aged 18 to 34 also experience by far the largest decline in MVA donors in response to helmet laws: 31 percent of the baseline donation rate $(=-0.526 / 1.716)$. Among men, the other age groups show much smaller relationships between helmet laws and fatalities, as well as much smaller effects of helmet laws on MVA organ donors, providing further support for a causal interpretation of the relationship between helmet laws and MVA donors among men aged 18 to $34 .{ }^{14}$ We also estimated these age- and gender-specific models using total organ donors as a dependent variable, rather than MVA donors. The results of these specifications, available upon request, are broadly similar to those shown in Table 4, albeit less precisely estimated - total donations among men and those aged 18-34 increase in response to helmet law repeals.

As a final set of specification tests, we next consider the effects of helmet laws on the supply of donors who were killed in accidents that did not involve motor vehicles. As noted

\footnotetext{
${ }^{13}$ We thank an anonymous referee for suggesting these specifications.

${ }^{14}$ We assessed the sensitivity of these central results to four functional form and measurement issues. First, because states enacted or repealed helmet laws in the middle of calendar years (see Appendix Table 1), we estimated all models using a measure of the fraction of the year in which a state's helmet law was in place as the key regressor. Second, we treated the dependent variable as a count variable, estimating all models by Poisson quasi-maximum likelihood, and alternatively measured it as the log of per capita death and donor rates. Third, we re-estimate equations (1) and (2) six times, each time dropping one of the six states that repealed its helmet law, in order to test the possibility that only one or two states are driving the results. Finally, we excluded from the analysis all DSAs that cover multiple states (such as the Kansas City-based DSA, which covers parts of both Kansas and Missouri) because the state in which a death occurred is ambiguous in these cases. None of these alternative specifications yielded substantively different results from the central ones reported in the text. All alternative results are available upon request.
} 
above, the principal threat to the validity of our central estimates lies in the possibility that statespecific unobserved trends in organ donation rates (or in organ extraction technology) may be correlated with the presence of helmet laws. It is plausible that these changes similarly affect all accident victims, regardless of whether the accidents involved motor vehicles. As a result, we view donors who died in non-motor vehicle accidents (NMVAs) as a more natural "control group" than the full set of donors who were not killed in MVAs (which includes those who died via homicides, suicides, and natural causes, in addition to those who died in NMVAs).

Table 5 presents three sets of age- and gender-specific estimates that comprise this final specification test. The first set, in columns (1), (4), and (7), simply reproduces the difference-indifference estimates for MVA donors shown in Table 4. The second set, in columns (2), (5), and (8), shows the analogous estimates based on specifications in which the dependent variable is the per capita supply of NMVA donors. Finally, the third set of estimates, in columns (3), (6), and (9), is the difference between the first two, representing a triple-difference that identifies the differential effect of helmet mandates on MVA donors relative to NMVA donors. On the whole, the results provide additional support that the central estimates in Table 4 capture real effects of helmet laws. NMVAs are not strongly associated with helmet laws in either the full sample or among those most likely to die in motorcycle accidents, that is, males and those aged 18-34. Among men aged 18-34, the NMVA estimate is -0.018 , compared to -0.526 for the MVA estimate, so the triple-difference estimate is $-0.508(=-0.526+0.018)$. The triple-difference estimates are also negative and statistically significant for males as a whole and in the pooledgender sample of those aged 18-34. In all other age and gender categories, the estimates are sometimes positive, sometimes negative, but always statistically insignificant. Note that the top row of column (9) shows that the triple-difference estimate is not statistically significant in the 
overall pooled-gender sample, partly because of a smaller point estimate compared to that in column (7) and partly because of decreased precision (the third difference introduces an additional source of noise to the full-sample estimates). Curiously, helmet laws are significantly negatively associated with female NMVA donors aged 35-49, but this finding appears to be an anomaly given that none of the other nine gender- and age- specific estimates are distinguishable from zero.

The estimates in Table 5 also shed light on whether motorcycle helmet laws reduce deaths and organ donations overall or merely shift deaths and donations between circumstances in a form of "crowd out". In particular, risk-lovers who die in motorcycle accidents may have instead pursued other risky activities had their state imposed a universal helmet law. ${ }^{15}$ Under this hypothesis, helmet laws would increase the supply of donors who died in NMVAs, leading to ambiguity in the overall effect of laws on the supply of donors who die in all accidents. As Table 5 shows, there is no evidence to support such a crowding out hypothesis: none of the NMVA estimates in the table is positive and significant. Among males aged 18-34, who are at the highest risk of all types of accidents and thus most likely to exhibit crowding out, the estimated effect of helmet laws on NMVAs is actually negative and insignificantly different from zero at $-0.018(0.031)$.

\section{The Dynamic Effects of Helmet Laws}

In order to highlight dynamic patterns that the point estimates in Tables 3-5 do not show, Figure 1 presents graphical evidence of the effects of helmet laws. Panel A shows yearly motorcycle fatality rates among men in two groups: those in the six states that repealed their universal helmet laws from 1994 to 2007 , and those in the 32 remaining states and D.C. For the

\footnotetext{
${ }^{15}$ We thank Anup Malani for suggesting this possibility to us.
} 
states in the former group, the $X$-axis measures the year relative to the state's law change, with zero denoting the year of the repeal, 1 denoting the following year, and so on. For each state without a law change, “year zero" was randomly generated to equal either 1997, 1998, 1999, 2000 , or 2003 with equal probability, because these years corresponded to actual law changes in the other group of states. As the figure shows, death rates in the two groups are roughly equal in the three years prior to the repeals, but starting in year zero deaths increase more rapidly in the treatment states than in the control states. By year 4, the death rates in the treatment states are 14.98 per million persons, compared to 11.88 in the control states.

Panel B of the figure shows MVA organ donation rates among men aged 18 to 34, separately for the treatment and control states. The divergence between the two groups of states is consistent with the estimate of $\gamma$ of -0.526 shown in Table $4-$ the difference between the series increases from roughly 0.15 in years minus 1 and zero to nearly 0.7 in year 4 . Note that the horizontal axis begins at minus 2 in Panel B because the earliest law repeal occurred in 1997, and the OPTN data do not allow for a clean distinction between MVA and non-MVA donors until 1995.

Perhaps surprisingly, Panels A and B imply that helmet law repeals cause gradual increases in both motorcyclist death rates and organ donation rates, rather than discrete changes in the year of the repeal. Panel C illustrates one reason why: per capita motorcycle registrations increase gradually following helmet law repeals. Registration rates increased by 42 percent over the four years following repeals, from 11.7 to 16.6 per thousand state residents. In the control states, registrations increased by 15 percent, reflecting increased ridership in the U.S. in the late 1990s and early 2000s. This pattern implies that at least some of the association between helmet 
laws and deaths results from an effect of helmet laws on motorcycle ridership. ${ }^{16}$ Although speculative, it is also possible that those induced to ride by the repeals are relatively risk-loving or accident-prone compared to those who rode while the laws were in place. In order to assess whether the patterns in Figure 1 are representative of the trends in each of the six treatment states, Appendix Figures 1A-1C show graphs analogous to the three panels of Figure 1 separately for each state. The individual states exhibit patterns that are similar (albeit noisier) to those found in the aggregated treatment group.

The lack of an immediate effect of helmet law repeals on motorcyclist deaths and organ donations may also reflect a gradual effect of repeals on helmet usage. Ulmer and Preusser (2003) show that observed helmet usage declined from 96 percent to 76 percent immediately following the elimination of Kentucky's universal law in 1998, but that usage continued to gradually decline over the next three years, falling to 56 percent in 2001 . In contrast, observational studies show that the introduction of helmet laws immediately increases helmet usage from roughly 55 percent to nearly 100 percent (Kraus et al., 1995).

The asymmetric effects of helmet law repeals and introductions on helmet usage imply corresponding asymmetries in the effects on death rates and organ donations. To illustrate the possibility that behavior responds more quickly to the introduction of helmet laws than to their repeal, Figure 2 shows motorcyclist registration and death rates for Florida, Texas, and California, the three most populous states with helmet law changes after $1990 .{ }^{17}$ The top panel shows registration rates in the three states, and the bottom panel shows death rates. Each graph

\footnotetext{
${ }^{16}$ In agreement with the evidence in Figure 1, models analogous to (2) with per capita registrations as the dependent variable point to large effects of helmet laws on registration rates. The coefficient on law $w_{s t}$ is -3.317 (0.675), implying that helmet laws decrease registrations by roughly 14 percent of the baseline registration rate of 23.374 per 1000 persons. Similarly, the estimated effects of helmet laws on death rates decrease slightly when the registration rate is included as a regressor, from -4.369 to -3.887 . All data on registrations come from the U.S. Department of Transportation; see http://www.fhwa.dot.gov/policy/ohpi/hss/index.cfm for data from recent years.

${ }^{17}$ California is included as a "control" rather than a "treatment" state in our analyses of organ donations because its law change occurred in 1992, before the donation data included circumstance of death.
} 
includes two series, one labeled "State with law change" based on data from the given state, and the other based on data from the 40 states which have neither repealed nor enacted helmet laws since 1990. Each series is normed to equal 1 in the first full year of a new regime, represented by the vertical lines in each graph; for example, Florida repealed their helmet law in July of 2000, so each series equals 1 in 2001 in the graphs labeled "Florida". The time patterns for Florida and Texas are similar to those shown in Figure 1, in that registrations and death rates were similar before the helmet repeals then rose gradually yet steadily relative to the control states following helmet law repeals. California, which introduced a universal helmet law in 1992, shows a much different pattern. Death rates dropped by 38 percent between 1991 and 1992 while registration rates changed only negligibly, suggesting that the sudden decline in deaths reflected increased helmet usage rather than a registration effect. Death rates declined an additional 40 percent from 1992 to 1998 , mirroring a 40 percent decline in registered motorcyclists over the same period.

The patterns in Figure 2 imply that the results shown above, which are based on an average of seven years of data following law changes, understate the long-run effects of repeals that gradually influence both registration rates and helmet usage. Moreover, because the timeframe of OPTN data availability covers six repeals and only one introduction, the estimates may understate both the short- and long-run impacts of helmet law introductions.

To further investigate the dynamic impacts of helmet law repeals, we estimated variants of specifications (1) and (2) that include a linear trend in the number of years since a state repealed its law, measured by the variable "years since repeal":

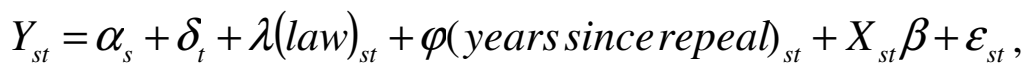


where $Y_{s t}$ refers to either deaths or donors per capita. ${ }^{18}$ For death rates, the pooled-gender estimates of $\lambda$ and $\varphi$ are -2.05 (with a standard error of 0.60 ) and 0.77 (0.15), respectively, implying an effect of $4.75(0.62)$ at 3.5 years after a repeal. This number is statistically indistinguishable from the pooled-gender estimate of 4.369 in Table 4 , which captures the effect at roughly 3.5 years following repeals because it is based on an average of seven years of postrepeal data. Similarly, in models of MVA organ donation rates, the pooled-gender estimates of $\lambda$ and $\varphi$ are $-0.27(0.23)$ and $0.10(0.05)$, implying an effect of $0.63(0.18)$ at 3.5 years following a repeal. The estimated effect rises to $0.77(0.21)$ after 5 years and to $0.98(0.27)$ after 7 years. In order to consider whether the treatment and control states had differential trends in fatalities and organ donations that were not due to variation in helmet laws, we also estimate variants of equation (3) that include state-specific linear time trends. The inclusion of these additional variables does not substantially change the point estimates. For death rates, the pooled-gender estimate of $\lambda$ declines to $-1.66(0.61)$ and the estimate of $\varphi$ increases to 0.85 (0.21), implying an effect of $4.64(0.72)$ at 3.5 years after a repeal, similar to (although slightly noisier) the effect of 4.75 implied by the specification that does not include state-specific trends. Similarly, the implied effect on MVA donation rates declines from 0.63 to $0.58(0.24)$ when state-specific linear trends are included in (3). Although for brevity's sake we do not report the full set of results based on equation (3), these estimates are available upon request.

Instrumental Variables Estimates of the Effect of Motorcyclist Deaths on Organ Donation Rates

The estimates of $\gamma$ from models (1) and (2) capture the reduced-form relationships between helmet laws and organ donors and between helmet laws and motorcyclist deaths,

\footnotetext{
${ }^{18} \mathrm{We}$ did not attempt to estimate dynamic effects of the introduction of Louisiana's law in 2004, primarily because we are hesitant to make inferences based on a single law change.
} 
respectively. As a result, the ratio of the two estimates of $\gamma$ represents a Wald IV estimate of the effect of motorcyclist death rates on organ donation rates. A causal interpretation of this ratio essentially requires that helmet laws only influence organ donation rates through their effect on motorcyclist deaths. Although we cannot formally test this assumption, the informal evidence presented above suggests that it holds. Specifically, because helmet laws appear unrelated to non-MVA donation rates and to female MVA donation rates, we interpret the estimated ratio as measuring a causal effect of motorcyclist deaths on organ donation rates.

The Wald IV estimates, shown in Panel B of Table 4, are 0.141 for men $(=0.558$ / 3.962), -0.037 for women $(=0.015 /-0.395)$, and 0.124 for the pooled-gender sample $(=0.543 / 4.369)$. These estimates capture the effect of the excess motorcyclist deaths resulting from state repeals of helmet laws on the supply of organ donors. ${ }^{19}$ Taken literally, the pooled-gender estimate implies that every motorcyclist death due to the lack of a universal helmet law produces 0.124 additional organ donors. For men aged 18 to 34 , this number increases to $0.261(=0.526 / 2.018)$. Based on the estimates of the sensitivity of organ donation rates to motorcyclist death rates, we can calculate the size of the positive externality resulting from each helmetless motorcyclist's death, as measured by possible lives saved. According to OPTN data, 2.7 organs are successfully transplanted per cadaveric donor, on average. Under the upper-bound assumption that each of these organs saves one life, the pooled-gender estimate of 0.124 implies that every death of a helmetless motorcyclist saves the lives of $0.33(=0.124 \times 2.7)$ individuals on organ transplant waiting lists. ${ }^{20}$ Because this upper-bound estimate is far less than one,

\footnotetext{
${ }^{19}$ For instrumental variables estimates to be interpreted as local average treatment effects, Imbens and Angrist (1994) show that a potential instrument must also satisfy the property of monotonicity. Although monotonicity is untestable in the context of a binary instrument such as $l a w_{s t}$, it is likely to hold in this setting - it implies that the presence of a helmet law does not increase motorcyclist death rates in any state.

${ }^{20}$ According to the 2007 OPTN annual report, one-year survival rates are 94 percent for kidney recipients, 87 percent for liver recipients, and 88 percent for heart recipients, accounting for the three most transplanted organs (Table 1.13). The same report shows that multiple organ transplants are very rare, accounting for fewer than 2
} 
helmetless riding is clearly an inefficient means of preserving life in the absence of a basis for making normative judgments about the value of one life relative to another. Nonetheless, this calculation highlights the possibility that helmet laws impact death rates even among those who do not ride motorcycles.

As a further gauge of the magnitude of the estimates in Table 4, recall that in 2007, 135.3 MVA fatalities resulted in 5.36 organ donors per million persons (see Tables 1 and 2). Each MVA death therefore produced 0.040 organ donors, and this overall donor rate, $D$, is a weighted average of the donor rates among helmetless motorcyclists $\left(D_{h m}\right)$ and all others involved in $\operatorname{MVAs}\left(D_{o}\right)$ :

$$
D=P \times D_{h m}+(1-P) \times D_{o}
$$

where $P$ is the proportion of all MVA fatalities that involve helmetless motorcyclists. The pooled-gender estimate of 0.124 represents an estimate of $D_{h m}$. Based on 2007 FARS national data on traffic fatalities, $P$ equals 0.050 , implying that $D_{o}$ equals 0.035 - while 12.4 percent of helmetless motorcyclists killed in MVAs eventually become organ donors, the analogous rate among all other MVA fatalities is only 3.5 percent. This discrepancy presumably results from higher rates of brain death among helmetless motorcyclists than among others killed in MVAs. Howard et al. (2007) estimate that 51 percent of viable donors actually become donors, so roughly 24 percent $(=0.124 / 0.51)$ of deceased motorcyclists are viable donors, i.e., brain dead but otherwise healthy. Although we are wary of interpreting this number literally because it is based on the assumption that consent rates among motorcyclists are equal to those in the rest of the population, to our knowledge it represents the first estimate of the fraction of deceased helmetless motorcycle riders who are viable organ donors.

percent of all transplants (Table 1.08). These numbers, and many others in this section, are taken from OPTN's rich national data available for public use on OPTN's website: http://optn.transplant.hrsa.gov/latestData/step2.asp. 


\section{Helmet Laws and the Excess Demand for Organs}

Finally, we consider the magnitude of the effect of helmet laws in the context of a broader question: how would eliminating all existing universal helmet laws affect annual organ donations and transplant waiting lists? According to state-level population estimates from the U.S. Census Bureau, approximately 155 million people lived in states with universal helmet laws in 2007. Based on the estimates from Table 4, which measure the average effect over the seven years following a law change, the repeal of all helmet laws would increase the annual number of deceased motorcyclists by roughly $677(=4.369 \times 155)$, or 13.2 percent of the 5,128 deaths in 2007. These deaths would produce $84(=0.543 \times 155)$ additional organ donors because 12.4 percent of deceased motorcyclists become donors. Based on OPTN's estimate of 2.7 transplanted organs per donor, 227 additional organs would be transplanted. Alternatively, the dynamic estimates from model (3) imply that 332 additional organs would be transplanted five years after a nationwide repeal. These numbers represent 3.1 and 4.6 percent, respectively, of the 7,287 individuals who died in 2007 while waiting for a transplant. ${ }^{21}$

\section{Conclusions}

Motorcycle helmet mandates are effective: consistent with a larger literature, our estimates indicate that state-level motorcyclist fatalities increase by approximately thirty percent when universal helmet laws are repealed. Despite the effectiveness of helmets in preventing

\footnotetext{
${ }^{21}$ The dramatic shortage of organs has generated a large body of research that evaluates mechanisms for increasing organ donation rates. Abadie and Gay (2006) find that countries using presumed consent donation standards have 25 to 30 percent higher donation rates than observationally similar countries using informed consent regimes. In a special issue of the Journal of Economic Perspectives addressing the excess demand for organs, Becker and Elias (2007) focus on financial incentives for increasing living donors, Howard (2007) reviews policies for increasing consent rates and the pool of potential donors, and Roth (2007) discusses the compensation of organ donors in light of "repugnance" for the market trading of organs. In a series of papers, Roth, Sonmez, and Unver $(2004,2005)$ design a matching mechanism for organ recipients and donors that has been implemented in New England.
} 
deaths, helmet usage rates in states without universal laws suggest that nearly half of all motorcyclists prefer to ride helmetless. Helmet mandates impose costs on these riders, but these costs may be justified by a reduction in the negative externalities imposed by those injured or killed in accidents.

This study is the first to assess the anecdotal belief that helmet laws also decrease the positive externalities of helmetless riding by reducing the supply of organ donors. Our central estimates show that organ donations due to motor vehicle accidents (MVAs) increase by 10 percent when states repeal helmet laws. Nearly all of this effect is concentrated among men, who account for over 90 percent of motorcyclist fatalities, and it is also concentrated among those aged 18 to 34 . Helmet laws are unrelated to the number of organ donors who died in circumstances other than MVAs, providing further support for a causal interpretation of the association between helmet laws and MVA donors. Under the upper-bound assumption that each recovered organ saves one life, the estimates imply that every motorcyclist death due to the lack of a helmet law saves the lives of 0.33 individuals on organ transplant waiting lists.

Quantifying the unintended consequences of helmet laws allows for more informed policymaking by providing a more complete picture of the associated costs and benefits. Based on our preferred estimates, 3.1 to 4.6 percent of those who died while awaiting an organ in 2007 would have instead received a transplant if all helmet laws were repealed. These estimates may understate the long-run impacts of helmet laws on organ donations, but they show that helmet laws profoundly affect the lives of some potential transplant recipients. This unintended consequence merits consideration in cost-benefit analyses of helmet laws, which currently focus on weighing the costs to society of helmetless motorcycling against motorcyclists' freedom of choice. 


\section{References:}

Abadie, Alberto and Sebastien Gay. 2006. "The Impact of Presumed Consent Legislation on Cadaveric Organ Donation: A Cross-Country Study.” Journal of Health Economics, 25: 599620.

Auman, Kimberly M., Joseph A. Kufera, Michael F. Ballesteros, John E. Smialek, Patricia C Dischinger. 2002. "Autopsy Study of Motorcyclist Fatalities: The Effect of the 1992 Maryland Motorcycle Helmet Use Law.” American Journal of Public Health, 92(8): 13521355.

Becker, Gary S. and Julio Jorge Elias. 2007. "Introducing Incentives in the Market for Live and Cadaveric Organ Donations." Journal of Economic Perspectives, 21(3): 3-24.

Berkowitz, A. 1981. The Effect of Motorcycle Helmet Usage on Head Injuries, and the Effect of Usage Laws on Helmet Wearing Rates. DOT HS 805 851. U.S. Department of Transportation, Washington, D.C.

Bledsoe, Gregory H. and Guohua Li. 2005. "Trends in Arkansas Motorcycle Trauma after Helmet Law Repeal.” Southern Medical Association, 98(4): 436-40..

Bledsoe, Gregory H., Stephen M. Schexnayder, Martin J. Carey, William N. Dobbins, William D. Gibson, Jason W. Hindman, Terry Collins, Bonny H. Wallace, John B. Cone, Thomas J. Ferrer. 2002. "The Negative Impact of the Repeal of the Arkansas Motorcycle Helmet Law." The Journal of Trauma Injury, Inflection, and Critical Care, 53(6): 1078-1087.

Dare, C.E., J.C. Owens, S. Krane. 1978. Impact of Motorcycle Helmet Usage in Colorado. DOT HS 803 680. U.S. Department of Transportation, Washington, D.C.

Dee, Thomas. 2009. "Motorcycle Helmets and Traffic Safety." Journal of Health Economics, 28(2): 398-412.

Eberhardt, M., E. Goldman, H. Stankewicz, S. Melanson. 2008. "Helmet Use May Affect Severity of Injuries Sustained in Motorcycle Accidents.” Annals of Emergency Medicine, 52(4): S109.

Gilbert, Hope, Neil Chaudhary, Mark Solomon, David Preusser, Linda Cosgrove. 2008. "Evaluation of the Reinstatement of the Universal Motorcycle Helmet Law in Louisiana." DOT HS 810 956. U.S. Department of Transportation, Washington, D.C. 
Guandagnoli, Edward, Cindy Christiansen, Carol Beasley. 2003. "Potential Organ-Donor Supply and Efficiency of Organ Procurement Organizations." Health Care Financing Review, 24(4): 101-10.

Houston, David J. and Lilliard E. Richardson. 2008. "Motorcyclist fatality rates and mandatory helmet-use laws." Accident Analysis \& Prevention, 40: 200-208.

Howard, David H., Laura A. Siminoff, Virginia McBride, and Monica Lin. 2007. "Does

Quality Improvement Work? Evaluation of the Organ Donation Breakthrough

Collaborative." Health Services Research, 42(6): 2160-2173.

Howard, David H. 2007. "Producing Organ Donors." Journal of Economic Perspectives, 21(3): 25-36.

Imbens, Guido and Joshua Angrist. 1994. "Identification and Estimation of Local Average Treatment Effects." Econometrica, 62(2): 467-476.

Kraus, J.F., C. Peek, D.L. McArthur, A. Williams. 1995. "The Effect of the 1992 California Motorcycle Helmet Use Law on Motorcycle Crash Fatalities and Injuries." Journal of the American Medical Association, 85(1): 1506-1511.

Kraus, J.F., C. Peek, A. Williams. 1994. "Compliance with the 1992 California Motorcycle Helmet Use Law.” American Journal of Public Health, 272(19): 96-99.

Liu, B.C., R. Ivers R. Norton, S. Boufous S. Blows S.K. Lo. 2008. Helmets for Preventing Injury in Motorcycle Riders. Cochrane Database of Systematic Reviews, Issue 1. Art. No.: CD004333. DOI: 10.1002/14651858.CD004333.pub3.

Lund, Adrian K, Allan F. Williams, Katie N. Womack. 1991. "Motorcycle Helmet Use in Texas." U.S. Department of Health and Human Services Public Health Report; 106: 576-578.

Mayrose, James. 2008. "The Effects of a Mandatory Motorcycle Helmet Law on Helmet Use and Injury Patterns among Motorcyclist Fatalities.” Journal of Safety Research, 39: 429-432.

Mertz, Kristen J. and Harold B. Weiss. 2008. "Changes in Motorcycle-Related Head Injury Deaths, Hospitalizations, and Hospital Charges Following Repeal of Pennsylvania's Mandatory Motorcycle Helmet Law.” American Journal of Public Health, 98(8): 14641467.

Muller, Andreas. 2004. "Florida's Motorcycle Helmet Law Repeal and Fatality Rates." American Journal of Public Health, 94(4): 556-558. 
Muller, Andreas. 2007. “Weakening Pennsylvania's Motorcycle Helmet Law: Preliminary Estimates." poster session at 2007 American Public Health Association annual meetings.

Preusser, D.F., J.H. Hedlund, R.G. Ulmer. 2000. Evaluation of Motorcycle Helmet Law Repeal in Arkansas and Texas. DOT HS 809 131. U.S. Department of Transportation, Washington, D.C.

Roth, Alvin E. 2007. "Repugnance as a Constraint on Markets." Journal of Economic Perspectives, 21(3): 37-58.

Roth, Alvin E., Tayfun Sönmez, and M. Utku Ünver. 2004. “Kidney Exchange.” The Quarterly Journal of Economics, 119(2): 457-488.

Roth, Alvin E., Tayfun Sönmez, and M. Utku Ünver. 2005. "Pairwise Kidney Exchange." Journal of Economic Theory, 125(2): 151-188.

Sass, T.R. and P.R. Zimmerman. 2000. "Motorcycle Helmet Laws and Motorcyclist Fatalities." Journal of Regulatory Economics, 18(3): 195-215.

Siminoff, Laura A., Nahida Gordon, Joan Hewlett, et al. 2001. "Factors Influencing Families' Consent for Donation of Solid Organs for Transplantation." Journal of the American Medical Association, 286(1): 71-77.

Struckman-Johnson, C. and V.S. Ellingstad. 1980. Impact of the Motorcycle Helmet Law Repeal in South Dakota 1976-79. DOT HS 805 619. U.S. Department of Transportation, Washington, D.C.

Ulmer, R.G. and V.S. Northrup. 2005. Evaluation of the Repeal of the All-Rider Motorcycle Helmet Law in Florida. DOT HS 809 849, U.S. Department of Transportation, Washington, D.C.

Ulmer, R.G. and D.F. Preusser. 2003. Evaluation of the Repeal of Motorcycle Helmet Laws in Kentucky and Louisiana. DOT HS 809 530, U.S. Department of Transportation, Washington, D.C.

U.S. Department of Transportation. Various years. "Highway Statistics.” Federal Highway Administration.

U.S. General Accountability Office GAO. 1991. Report to Congressional Requesters Highway Safety: Motorcycle Helmet Laws Save Lives and Reduce Costs to Society. GAO/RCED-91170. Wasthington, DC. 
Table 1: Organ Donors by Year, Gender, and Circumstance, per Million Persons

\begin{tabular}{lcccccc} 
& \multicolumn{3}{c}{ Circumstance: Motor } & \multicolumn{3}{c}{ Circumstance: } \\
& \multicolumn{3}{c}{ Vehicle Accident } & \multicolumn{3}{c}{ Others } \\
\hline 1994 & All & Male & Female & All & Male & Female \\
1995 & 4.05 & 2.71 & 1.34 & 15.87 & 9.50 & 6.37 \\
1996 & 5.43 & 3.55 & 1.89 & 15.29 & 8.90 & 6.39 \\
1997 & 5.16 & 3.44 & 1.73 & 15.52 & 8.88 & 6.64 \\
1998 & 5.25 & 3.39 & 1.87 & 15.45 & 8.84 & 6.60 \\
1999 & 5.19 & 3.40 & 1.80 & 16.36 & 9.11 & 7.25 \\
2000 & 4.94 & 3.24 & 1.70 & 16.41 & 9.02 & 7.39 \\
2001 & 5.24 & 3.52 & 1.72 & 16.43 & 9.10 & 7.33 \\
2002 & 4.92 & 3.37 & 1.55 & 16.84 & 9.41 & 7.43 \\
2003 & 5.20 & 3.55 & 1.65 & 16.71 & 9.54 & 7.17 \\
2004 & 5.03 & 3.33 & 1.70 & 17.63 & 9.97 & 7.66 \\
2005 & 5.30 & 3.54 & 1.77 & 19.43 & 10.68 & 8.75 \\
2006 & 5.24 & 3.50 & 1.73 & 20.69 & 11.57 & 9.12 \\
2007 & 5.64 & 3.86 & 1.78 & 21.68 & 12.41 & 9.26 \\
& 5.36 & 3.74 & 1.61 & 21.85 & 12.68 & 9.15
\end{tabular}

Note:

OPTN began reporting circumstances of death on April 1, 1994. For the first three months of 1994, all donors are included in the "All Others" category. Source: OPTN. 
Table 2: Motor Vehicle Fatalities by Gender, per Million Persons

\begin{tabular}{|c|c|c|c|c|c|c|c|c|c|}
\hline \multirow[b]{2}{*}{ Year } & \multicolumn{3}{|c|}{ All MVA } & \multicolumn{3}{|c|}{ All Motorcycle Fatalities } & \multicolumn{3}{|c|}{ All Other Vehicles } \\
\hline & All & Male & Female & All & Male & Female & All & Male & Female \\
\hline 1994 & $1 \overline{56.3}$ & $\overline{105.3}$ & 51.1 & $\overline{8.9}$ & $\overline{8.1}$ & 0.8 & $1 \overline{47.4}$ & $\overline{97.2}$ & 50.3 \\
\hline 1995 & 159.0 & 107.0 & 52.0 & 8.5 & 7.7 & 0.8 & 150.5 & 99.3 & 51.2 \\
\hline 1996 & 158.5 & 105.7 & 52.7 & 8.1 & 7.4 & 0.7 & 150.3 & 98.3 & 52.0 \\
\hline 1997 & 156.8 & 103.9 & 52.9 & 7.9 & 7.2 & 0.7 & 148.9 & 96.7 & 52.2 \\
\hline 1998 & 153.4 & 102.1 & 51.3 & 8.5 & 7.7 & 0.8 & 144.9 & 94.4 & 50.6 \\
\hline 1999 & 152.8 & 102.8 & 50.1 & 9.1 & 8.3 & 0.8 & 143.7 & 94.5 & 49.2 \\
\hline 2000 & 148.4 & 101.0 & 47.4 & 10.2 & 9.3 & 1.0 & 138.1 & 91.7 & 46.4 \\
\hline 2001 & 146.5 & 100.6 & 45.9 & 11.1 & 10.1 & 1.0 & 135.4 & 90.5 & 44.9 \\
\hline 2002 & 148.9 & 102.1 & 46.9 & 11.3 & 10.3 & 1.1 & 137.6 & 91.8 & 45.8 \\
\hline 2003 & 147.1 & 100.7 & 46.4 & 12.7 & 11.5 & 1.3 & 134.4 & 89.2 & 45.2 \\
\hline 2004 & 145.8 & 100.2 & 45.6 & 13.7 & 12.2 & 1.5 & 132.1 & 88.0 & 44.1 \\
\hline 2005 & 146.8 & 102.4 & 44.4 & 15.4 & 13.9 & 1.5 & 131.3 & 88.4 & 42.9 \\
\hline 2006 & 140.7 & 98.5 & 42.2 & 15.9 & 14.6 & 1.4 & 124.8 & 84.0 & 40.8 \\
\hline 2007 & 135.3 & 95.7 & 39.6 & 17.0 & 15.4 & 1.5 & 118.3 & 80.2 & 38.0 \\
\hline
\end{tabular}

Note:

Authors' calculations using Fatality Analysis Reporting System (FARS) data. 
Table 3: Estimates of the Effect of Helmet Laws on Organ Donations

\begin{tabular}{|c|c|c|c|c|c|c|}
\hline \multirow[b]{3}{*}{ Donor Circumstance } & \multicolumn{3}{|c|}{ Organ Donors Measured i } & \multirow{3}{*}{$\begin{array}{l}\text { Natural } \\
\text { Logs } \\
(4) \\
\end{array}$} & \multirow{3}{*}{$\begin{array}{c}\text { Sample } \\
\text { Mean } \\
\text { (per Capita) }\end{array}$} & \multirow{3}{*}{$\begin{array}{c}\text { Sample } \\
\text { Mean } \\
\text { (Levels) }\end{array}$} \\
\hline & \multicolumn{2}{|c|}{ Per Capita } & \multirow{2}{*}{$\begin{array}{c}\text { Levels } \\
(3) \\
\end{array}$} & & & \\
\hline & (1) & (2) & & & & \\
\hline Motor Vehicle Accident & $\begin{array}{l}-0.491 \\
(0.157)\end{array}$ & $\begin{array}{l}-0.543 \\
(0.137)\end{array}$ & $\begin{array}{l}-7.696 \\
(1.975)\end{array}$ & $\begin{array}{l}-0.097 \\
(0.031)\end{array}$ & 5.148 & 60.595 \\
\hline All Others & $\begin{array}{c}0.843 \\
(1.283)\end{array}$ & $\begin{array}{c}0.046 \\
(1.005)\end{array}$ & $\begin{array}{c}6.215 \\
(10.545)\end{array}$ & $\begin{array}{c}0.047 \\
(0.043)\end{array}$ & 17.668 & 227.051 \\
\hline $\begin{array}{l}\text { Accidents Not Involving } \\
\text { Vehicles }\end{array}$ & $\begin{array}{l}-0.039 \\
(0.233)\end{array}$ & $\begin{array}{l}-0.234 \\
(0.215)\end{array}$ & $\begin{array}{l}-2.090 \\
(2.410)\end{array}$ & $\begin{array}{l}-0.106 \\
(0.116)\end{array}$ & 1.931 & 23.978 \\
\hline $\begin{array}{l}\text { Homicide, Suicide, or } \\
\text { Child Abuse }\end{array}$ & $\begin{array}{c}0.421 \\
(0.267)\end{array}$ & $\begin{array}{c}0.363 \\
(0.251)\end{array}$ & $\begin{array}{c}5.783 \\
(3.873)\end{array}$ & $\begin{array}{c}0.094 \\
(0.058)\end{array}$ & 3.390 & 43.516 \\
\hline Natural Causes & $\begin{array}{l}-0.020 \\
(1.348)\end{array}$ & $\begin{array}{l}-0.791 \\
(1.295)\end{array}$ & $\begin{array}{l}-9.762 \\
(11.534)\end{array}$ & $\begin{array}{l}0.508 \\
(0.634)\end{array}$ & 4.086 & 49.795 \\
\hline None of the Above & $\begin{array}{c}0.466 \\
(2.229)\end{array}$ & $\begin{array}{c}0.546 \\
(2.160)\end{array}$ & $\begin{array}{c}13.944 \\
(33.168)\end{array}$ & $\begin{array}{l}0.258 \\
(0.361)\end{array}$ & 7.922 & 105.703 \\
\hline $\begin{array}{l}\text { Include State-Year } \\
\text { Controls? }\end{array}$ & No & Yes & Yes & Yes & & \\
\hline
\end{tabular}

Notes:

1) All estimation samples consist of 38 states from 1994 to 2007. The unit of observation is a state-year. All models include indicators for years and states.

2) Models in column (2) add controls for the state maximum speed limit, quadratics in the total population of the state, the age distribution of the state's population, heating degree days, annual precipitation, and indicators for whether the state has a donor registry, whether the state allows online donor registration, whether organs can be donated without the consent of family members of the prospective donor, and whether the state had primary enforcement of seat belt laws.

3) Standard errors, in parentheses, are robust to clustering within state over time. 


\section{Table 4: Estimates of the Effect of Helmet Laws on per Capita Motorcycle Fatalities and Organ Donations, by Gender and Age}

Panel A: The Effect of Helmet Laws on Fatalities and MVA Donations

\begin{tabular}{|c|c|c|c|c|c|}
\hline \multicolumn{2}{|c|}{ Males } & \multicolumn{2}{|c|}{ Females } & \multicolumn{2}{|c|}{ Pooled } \\
\hline $\begin{array}{l}\text { Motorcycle } \\
\text { Fatalities } \\
(1)\end{array}$ & $\begin{array}{c}\text { MVA Organ } \\
\text { Donors } \\
(2)\end{array}$ & $\begin{array}{c}\text { Motorcycle } \\
\text { Fatalities } \\
\text { (3) }\end{array}$ & $\begin{array}{l}\text { MVA Organ } \\
\text { Donors } \\
\text { (4) }\end{array}$ & $\begin{array}{l}\text { Motorcycle } \\
\text { Fatalities } \\
\text { (5) }\end{array}$ & $\begin{array}{l}\text { MVA Organ } \\
\text { Donors } \\
(6)\end{array}$ \\
\hline $\begin{array}{c}-3.962 \\
(0.518)\end{array}$ & $\begin{array}{l}-0.558 \\
(0.109)\end{array}$ & $\begin{array}{l}-0.395 \\
(0.095)\end{array}$ & $\begin{array}{c}0.015 \\
(0.061)\end{array}$ & $\begin{array}{l}-4.369 \\
(0.568)\end{array}$ & $\begin{array}{l}-0.543 \\
(0.137)\end{array}$ \\
\hline [10.218] & [3.445] & [1.039] & [1.702] & [11.258] & [5.148] \\
\hline
\end{tabular}

Age Categories:

$\begin{array}{ccccccc}\text { Overall } & -3.962 & -0.558 & -0.395 & 0.015 & -4.369 & -0.543 \\ & (0.518) & (0.109) & (0.095) & (0.061) & (0.568) & (0.137) \\ & {[10.218]} & {[3.445]} & {[1.039]} & {[1.702]} & {[11.258]} & {[5.148]} \\ \begin{array}{c}\text { Age Categories: } \\ \text { <18 }\end{array} & & & & & & \\ & -0.103 & 0.047 & -0.015 & 0.092 & -0.118 & 0.139 \\ & (0.045) & (0.055) & (0.016) & (0.072) & (0.047) & (0.101) \\ 18-34 & {[0.237]} & {[0.884]} & {[0.039]} & {[0.601]} & {[0.276]} & {[1.486]} \\ & & & & & & \\ & -2.018 & -0.526 & -0.149 & -0.041 & -2.166 & -0.568 \\ 35-49 & (0.305) & (0.122) & (0.050) & (0.049) & (0.323) & (0.136) \\ & {[4.759]} & {[1.716]} & {[0.352]} & {[0.679]} & {[5.110]} & {[2.395]} \\ & -0.987 & -0.017 & -0.236 & -0.022 & -1.222 & -0.039 \\ & (0.170) & (0.098) & (0.049) & (0.049) & (0.181) & (0.138) \\ 50-64 & {[3.297]} & {[0.592]} & {[0.454]} & {[0.286]} & {[3.751]} & {[0.878]} \\ & & & & & & \\ & -0.709 & -0.069 & -0.018 & -0.008 & -0.730 & -0.077 \\ & (0.150) & (0.027) & (0.037) & (0.030) & (0.163) & (0.052) \\ 65+ & {[1.615]} & {[0.219]} & {[0.172]} & {[0.107]} & {[1.787]} & {[0.326]} \\ & & & & & & \\ & -0.146 & 0.008 & 0.012 & -0.007 & -0.134 & 0.001 \\ & (0.061) & (0.010) & (0.016) & (0.006) & (0.064) & (0.011) \\ & {[0.311]} & {[0.034]} & {[0.022]} & {[0.028]} & {[0.333]} & {[0.063]}\end{array}$

Panel B: The Effect of Motorcyclist Deaths on MVA Donation Rates

\begin{tabular}{cccc} 
& Males & Females & Pooled \\
\cline { 2 - 3 } & 0.141 & -0.037 & 0.124 \\
$(0.045)$ & $(0.256)$ & $(0.039)$
\end{tabular}

Notes:

1) All estimation samples consist of 38 states from 1994 to 2007. The unit of observation is a state-year. All models include indicators for years and states.

2) All models include the state-year controls described in the notes to Table 3.

3) Standard errors, in parentheses, are robust to clustering within state over time.

4) Sample means for relevant dependent variables are listed in brackets. 
Table 5: Estimates of the Effects of Helmet Laws on per Capita MVA, NMVA, and Differenced Organ Donations, by Gender and Age

\begin{tabular}{|c|c|c|c|c|c|c|c|c|c|}
\hline & & Males & & & Female & & & Poolec & \\
\hline & $\begin{array}{l}\text { MVAs } \\
(1)\end{array}$ & $\begin{array}{c}\text { NMVAs } \\
(2)\end{array}$ & $\begin{array}{c}\text { Difference } \\
(3)\end{array}$ & $\begin{array}{c}\text { MVAs } \\
(4)\end{array}$ & $\begin{array}{c}\text { NMVAs } \\
(5)\end{array}$ & $\begin{array}{c}\text { Difference } \\
(6)\end{array}$ & $\begin{array}{c}\text { MVAs } \\
(7)\end{array}$ & $\begin{array}{c}\text { NMVAs } \\
(8)\end{array}$ & $\begin{array}{c}\text { Difference } \\
(9)\end{array}$ \\
\hline Overall & $\begin{array}{l}-0.558 \\
(0.109)\end{array}$ & $\begin{array}{l}-0.130 \\
(0.119)\end{array}$ & $\begin{array}{l}-0.428 \\
(0.113)\end{array}$ & $\begin{array}{c}0.015 \\
(0.061)\end{array}$ & $\begin{array}{l}-0.104 \\
(0.109)\end{array}$ & $\begin{array}{c}0.119 \\
(0.105)\end{array}$ & $\begin{array}{l}-0.543 \\
(0.137)\end{array}$ & $\begin{array}{l}-0.234 \\
(0.215)\end{array}$ & $\begin{array}{l}-0.309 \\
(0.193)\end{array}$ \\
\hline $\begin{array}{c}\text { Age Categ } \\
<18\end{array}$ & $\begin{array}{c}0.047 \\
(0.055)\end{array}$ & $\begin{array}{c}0.011 \\
(0.067)\end{array}$ & $\begin{array}{c}0.036 \\
(0.087)\end{array}$ & $\begin{array}{c}0.092 \\
(0.072)\end{array}$ & $\begin{array}{c}0.015 \\
(0.031)\end{array}$ & $\begin{array}{c}0.077 \\
(0.096)\end{array}$ & $\begin{array}{c}0.139 \\
(0.101)\end{array}$ & $\begin{array}{c}0.026 \\
(0.086)\end{array}$ & $\begin{array}{c}0.112 \\
(0.162)\end{array}$ \\
\hline $18-34$ & $\begin{array}{l}-0.526 \\
(0.122)\end{array}$ & $\begin{array}{l}-0.018 \\
(0.031)\end{array}$ & $\begin{array}{l}-0.508 \\
(0.096)\end{array}$ & $\begin{array}{c}-0.041 \\
(0.049)\end{array}$ & $\begin{array}{c}0.002 \\
(0.025)\end{array}$ & $\begin{array}{l}-0.044 \\
(0.051)\end{array}$ & $\begin{array}{l}-0.568 \\
(0.136)\end{array}$ & $\begin{array}{l}-0.016 \\
(0.045)\end{array}$ & $\begin{array}{l}-0.552 \\
(0.108)\end{array}$ \\
\hline $35-49$ & $\begin{array}{l}-0.017 \\
(0.098)\end{array}$ & $\begin{array}{l}-0.060 \\
(0.051)\end{array}$ & $\begin{array}{c}0.043 \\
(0.128)\end{array}$ & $\begin{array}{l}-0.022 \\
(0.049)\end{array}$ & $\begin{array}{l}-0.094 \\
(0.036)\end{array}$ & $\begin{array}{c}0.072 \\
(0.060)\end{array}$ & $\begin{array}{l}-0.039 \\
(0.138)\end{array}$ & $\begin{array}{l}-0.154 \\
(0.074)\end{array}$ & $\begin{array}{c}0.115 \\
(0.165)\end{array}$ \\
\hline $50-64$ & $\begin{array}{l}-0.069 \\
(0.027)\end{array}$ & $\begin{array}{l}-0.019 \\
(0.039)\end{array}$ & $\begin{array}{l}-0.050 \\
(0.045)\end{array}$ & $\begin{array}{l}-0.008 \\
(0.030)\end{array}$ & $\begin{array}{l}-0.020 \\
(0.032)\end{array}$ & $\begin{array}{c}0.012 \\
(0.057)\end{array}$ & $\begin{array}{c}-0.077 \\
(0.052)\end{array}$ & $\begin{array}{l}-0.039 \\
(0.044)\end{array}$ & $\begin{array}{l}-0.038 \\
(0.070)\end{array}$ \\
\hline $65+$ & $\begin{array}{c}0.008 \\
(0.010)\end{array}$ & $\begin{array}{l}-0.043 \\
(0.033)\end{array}$ & $\begin{array}{c}0.051 \\
(0.036)\end{array}$ & $\begin{array}{l}-0.007 \\
(0.006)\end{array}$ & $\begin{array}{l}-0.008 \\
(0.019)\end{array}$ & $\begin{array}{c}0.001 \\
(0.017)\end{array}$ & $\begin{array}{c}0.001 \\
(0.011)\end{array}$ & $\begin{array}{l}-0.051 \\
(0.051)\end{array}$ & $\begin{array}{c}0.052 \\
(0.050)\end{array}$ \\
\hline
\end{tabular}

Notes:

1) All estimation samples consist of 38 states from 1994 to 2007. The unit of observation is a state-year.

2) All models include the state-year controls described in the notes to Table 3.

3) Standard errors, in parentheses, are robust to clustering within state over time. 
Figure 1
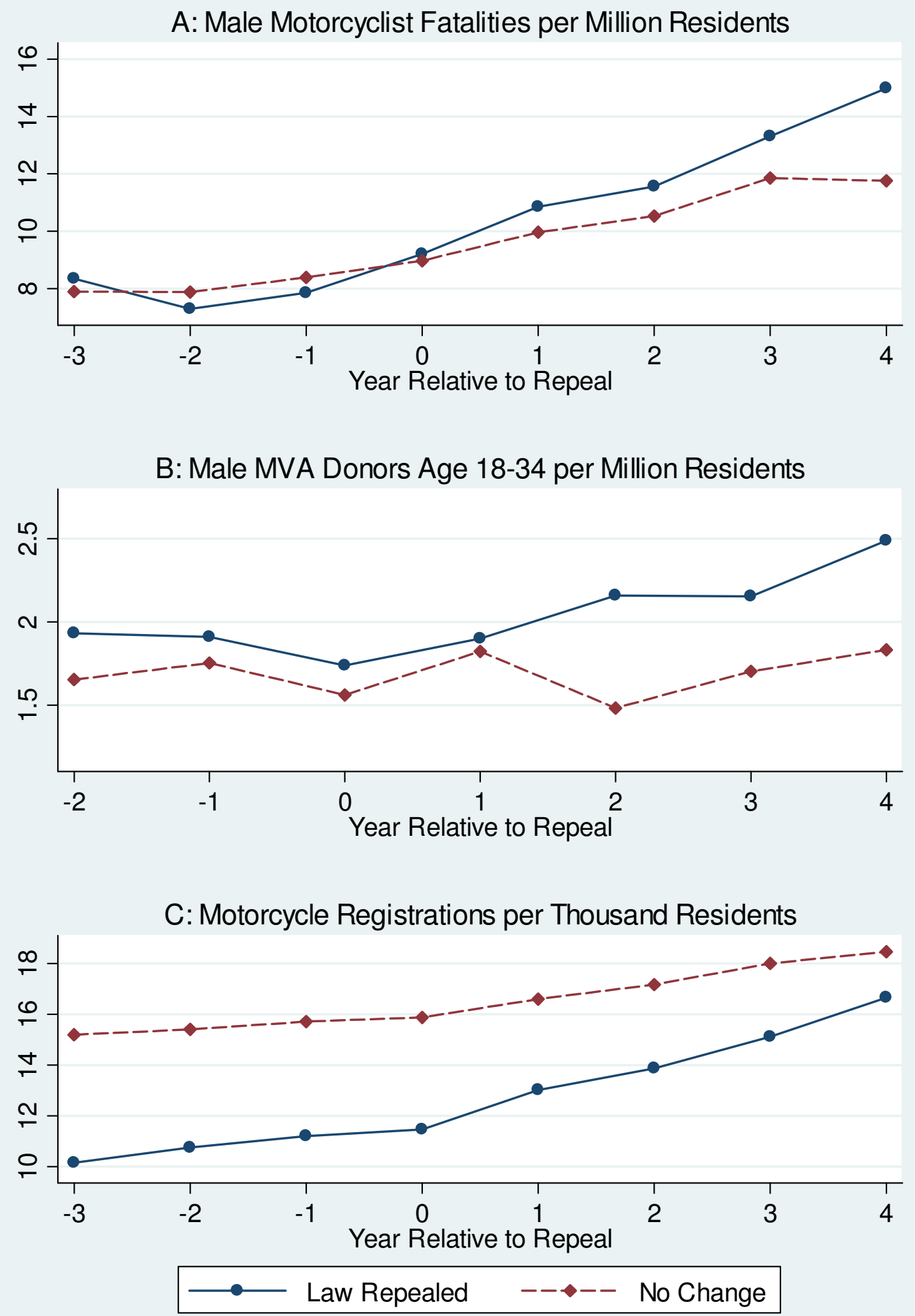

Note: Authors' calculations from FARS, OPTN and Department of Transportation data, 1994-2007. 
Figure 2

Per Capita Motorcyclist Registrations (Top) and Death Rates (Bottom) in Three Large States
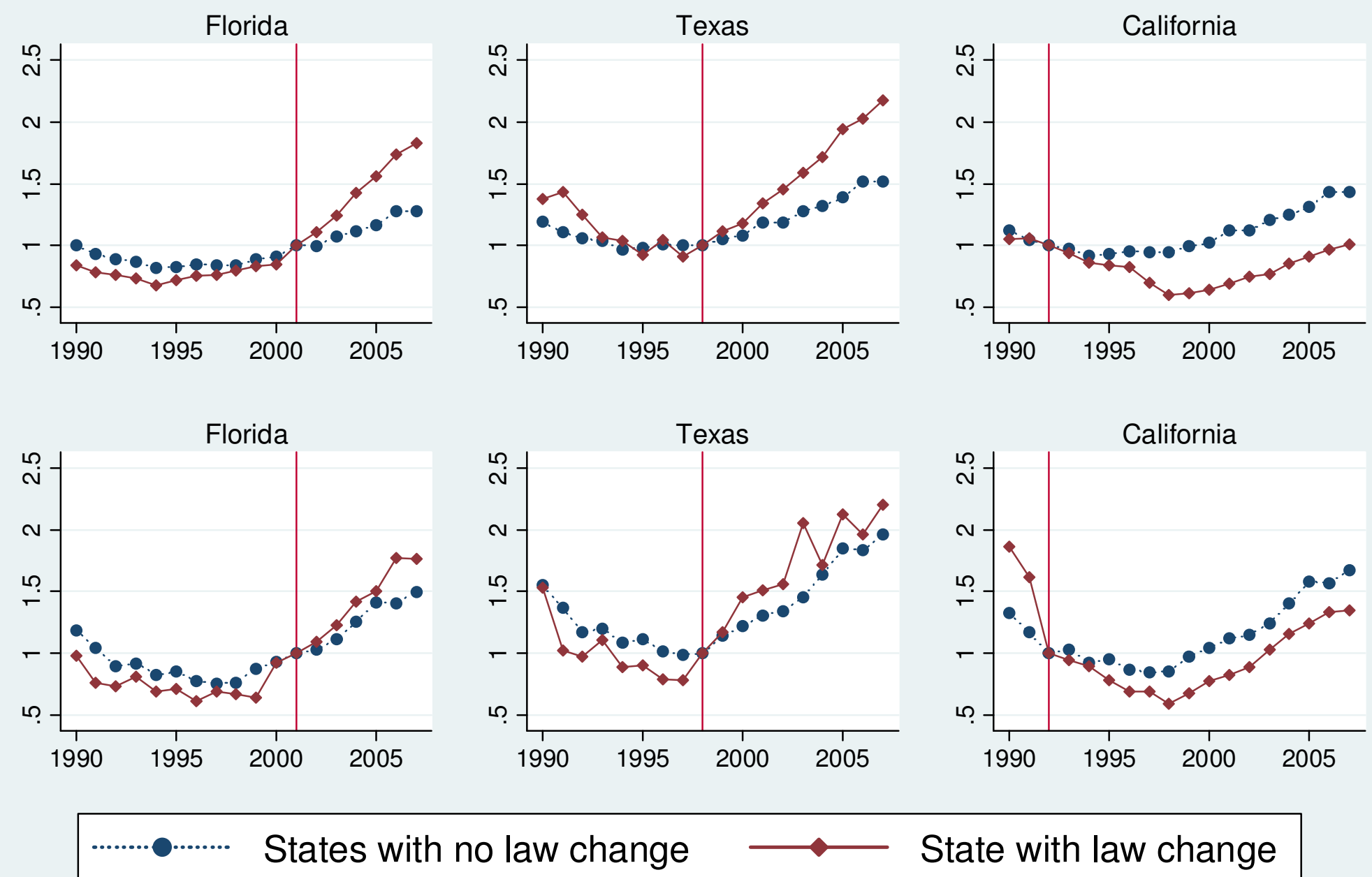

Note: Authors' calculations from FARS and Department of Transportation data. Data are normed to 1 in the first full year following a law change. 


\section{Appendix Table 1: Changes in State Helmet Laws, 1994-2007}

\begin{tabular}{|c|c|c|c|c|}
\hline \multirow{2}{*}{\multicolumn{2}{|c|}{$\begin{array}{l}\text { Year None to Partial } \\
1994\end{array}$}} & \multirow{2}{*}{ Universal to Partial } & \multirow[t]{2}{*}{ Partial to Universal } & \multirow{2}{*}{ Partial to None } \\
\hline & & & & \\
\hline \multicolumn{2}{|c|}{$\begin{array}{l}1994 \\
1995\end{array}$} & $\begin{array}{l}\text { AR (8), TX (9) } \\
\text { KY (7) } \\
\text { LA (8) } \\
\text { FL (7) }\end{array}$ & & \\
\hline \multicolumn{5}{|c|}{ 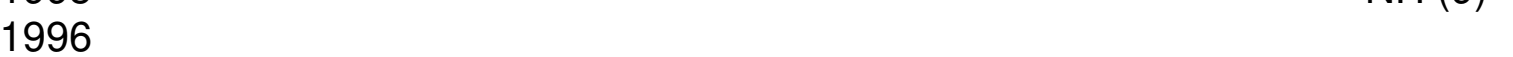 } \\
\hline & \multirow{4}{*}{$\begin{array}{c}\text { AR (8), TX (9) } \\
\text { KY (7) } \\
\text { LA (8) } \\
\text { FL (7) }\end{array}$} & & \\
\hline \multicolumn{2}{|l|}{1998} & & & \\
\hline \multicolumn{2}{|l|}{1999} & & & \\
\hline \multicolumn{2}{|l|}{2000} & & & \\
\hline \multicolumn{5}{|c|}{ and } \\
\hline \multicolumn{5}{|l|}{2002} \\
\hline \multicolumn{2}{|l|}{2003} & \multirow{4}{*}{ PA (9) } & \multirow{4}{*}{ LA (8) } & \\
\hline \multicolumn{2}{|l|}{2004} & & & \\
\hline \multicolumn{5}{|l|}{2005} \\
\hline \multicolumn{2}{|l|}{2006} & & & \\
\hline 2007 & CO (7) & & & \\
\hline
\end{tabular}

Note:

The month a law changed is listed in parentheses, where "1" denotes January, "2" denotes February, and so on. Source: Insurance Institute for Highway Safety: http://www.iihs.org/laws/default.aspx 


\section{Appendix Figure 1A}

\section{Per Capita Male Motorcyclist Fatalities in Six States}

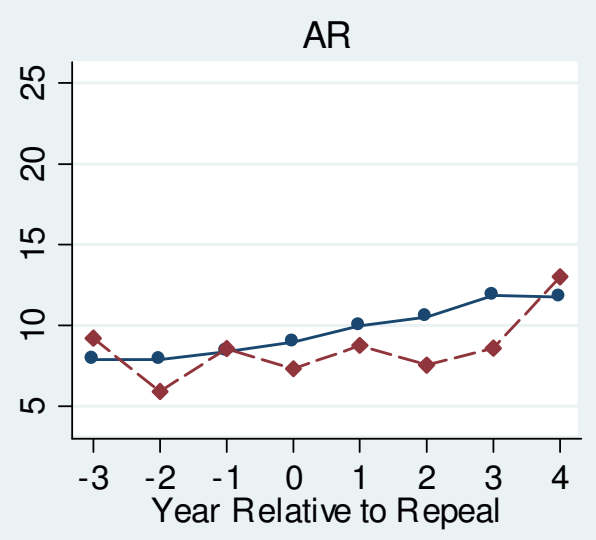

FL

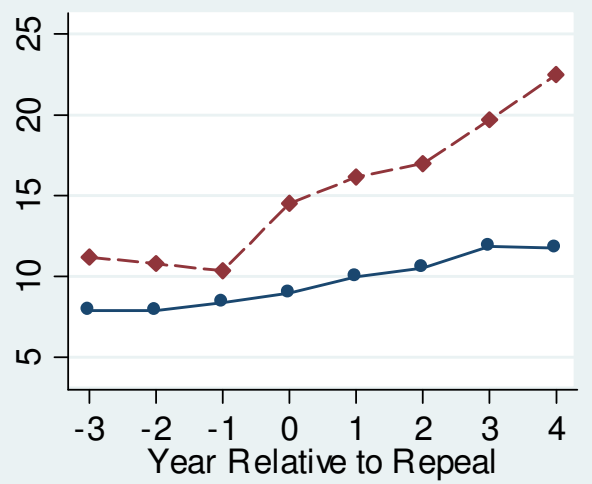

PA

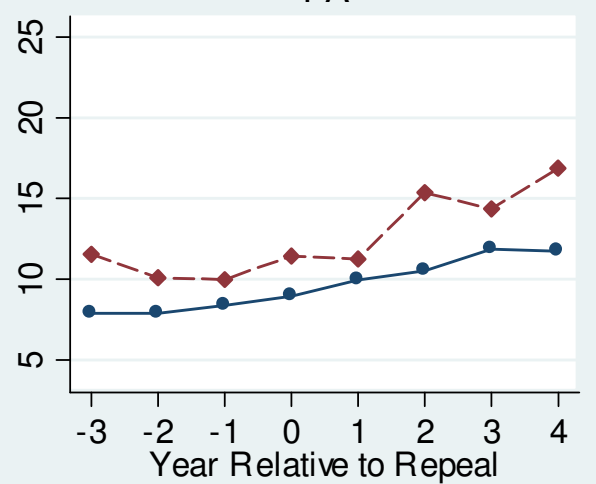

KY

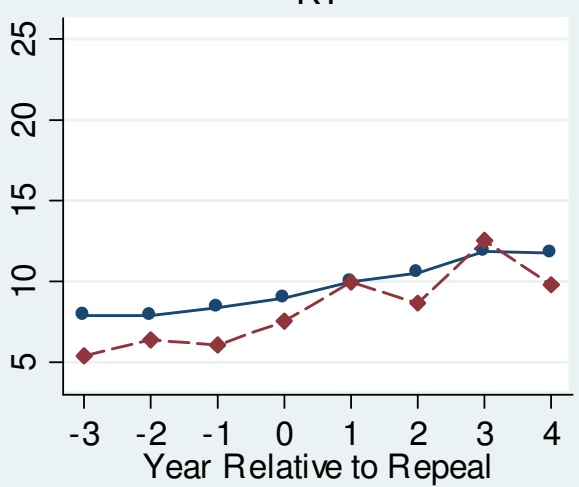

TX

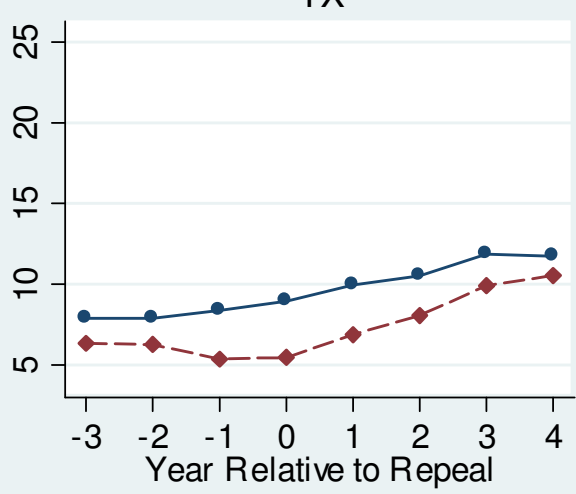

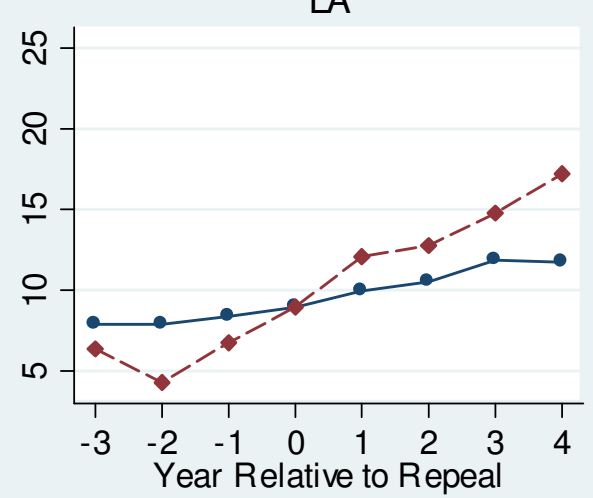

\section{States with no law change}

\section{State w ith law change}

Note: Authors' calculations from FARS data, 1994-2007. 


\section{Appendix Figure 1B}

\section{Per Capita Male MVA Organ Donors Aged 18-34 in Six States}

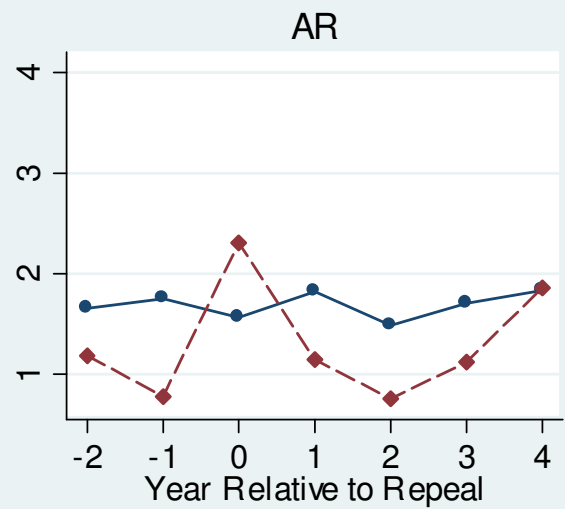

FL

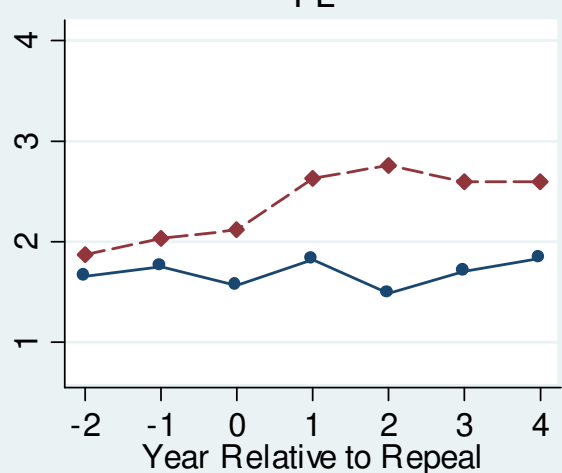

LA

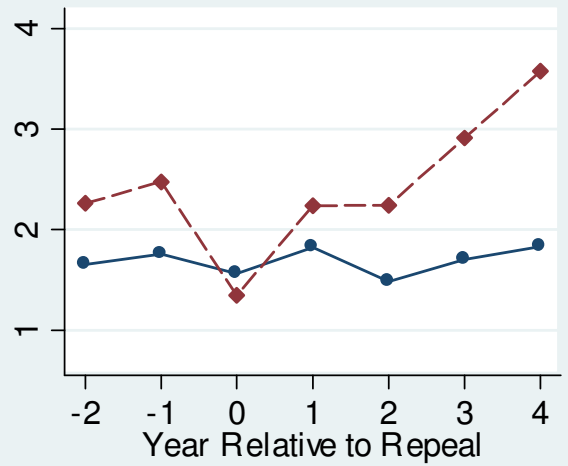

PA

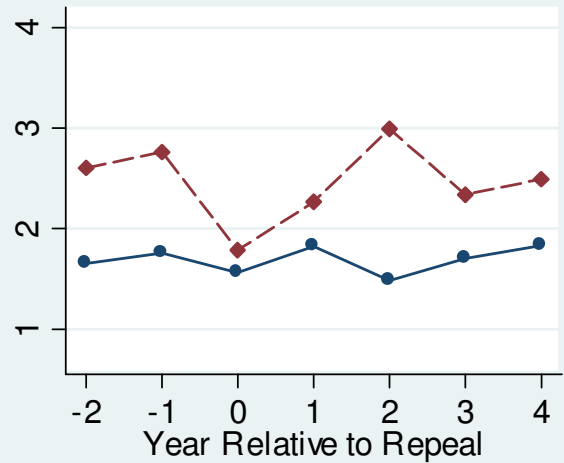

KY

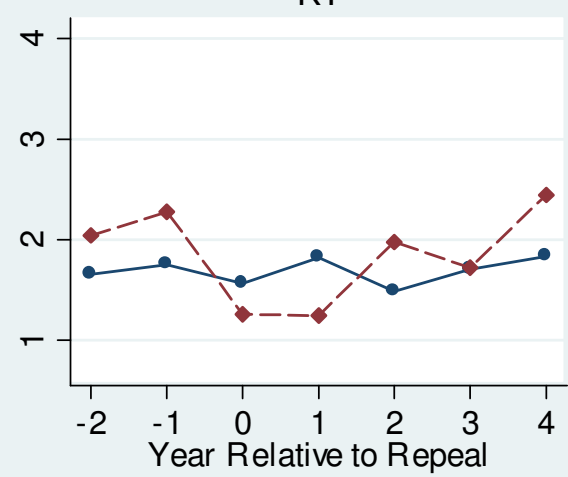

$\mathrm{TX}$

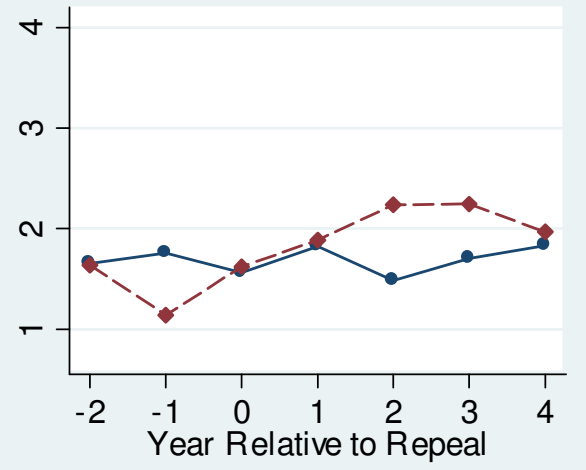

$\longrightarrow$ States with no law change $\quad---\bullet---$ State with law change

Note: Authors' calculations from OPTN data, 1994-2007. 


\section{Appendix Figure 1C}

\section{Per Capita Motorcycle Registrations in Six States}

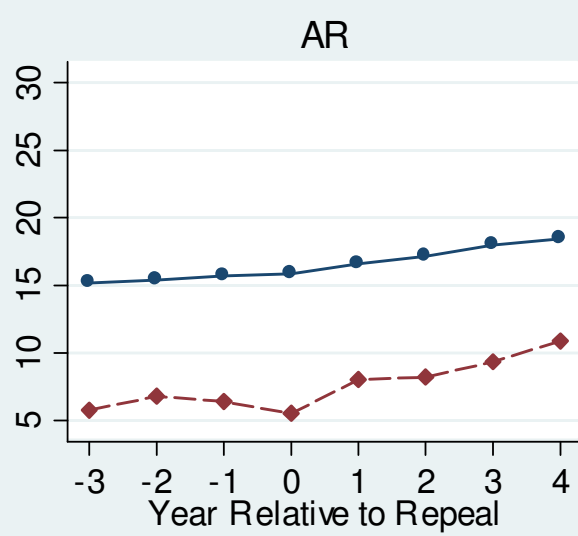

$\mathrm{FL}$

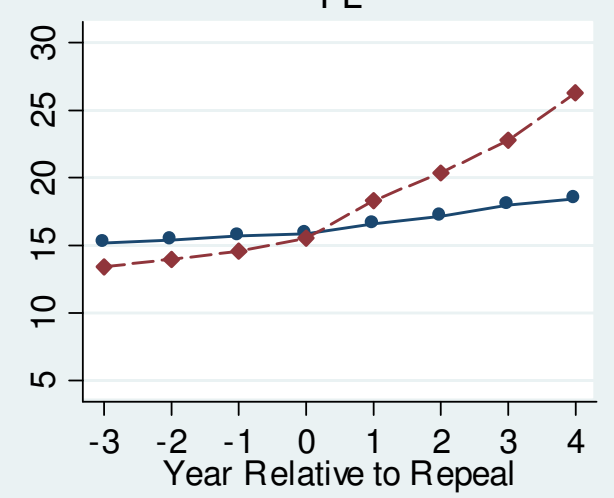

LA

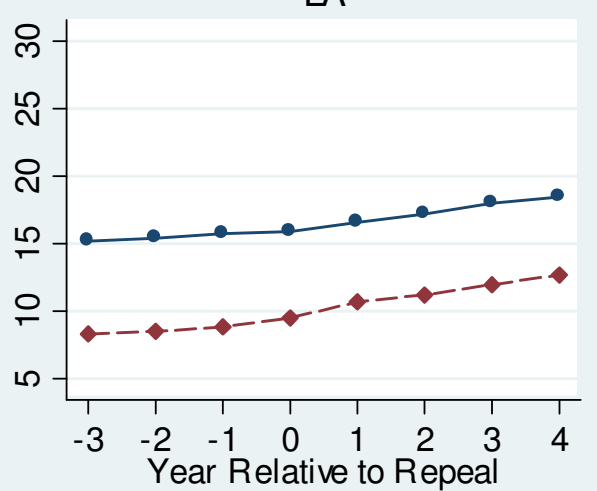

PA

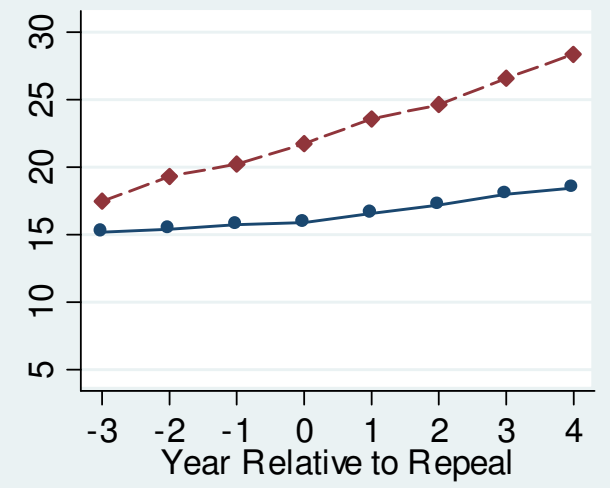

KY

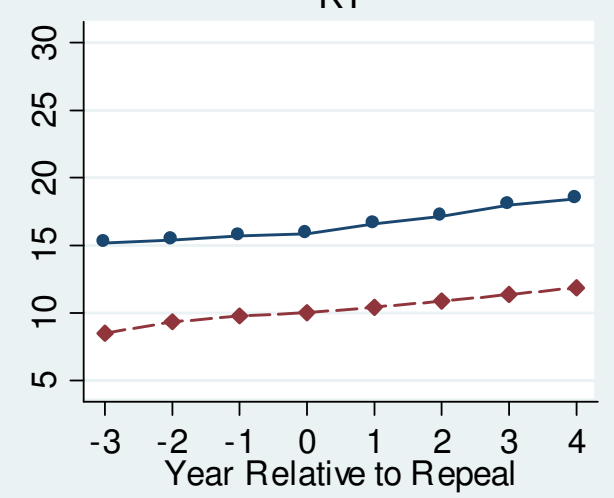

$\mathrm{TX}$

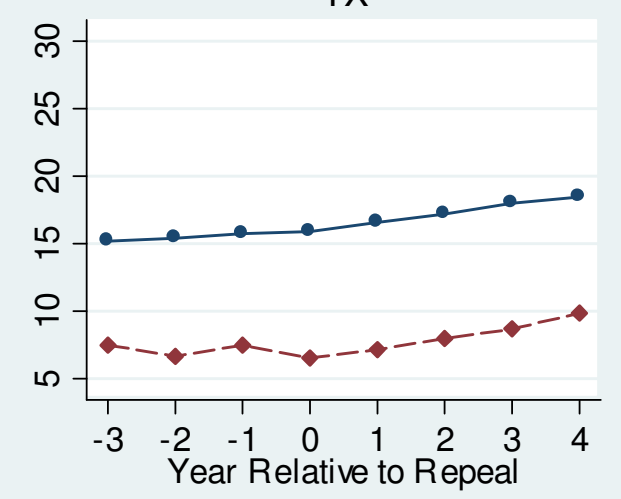

States w ith no law change

\section{State with law change}

Note: Authors' calculations from Department of Transportation data, 1994-2007. 